\title{
Computerized Training of Working Memory for Patients with Acquired Brain Injury
}

\author{
Lovisa Hellgren"1, Kersti Samuelsson², Anna Lundqvist², Björn Börsbo ${ }^{1,2^{*}}$ \\ ${ }^{1}$ Clinical Department of Rehabilitation Medicine, County Hospital Ryhov, Jönköping, Sweden \\ ${ }^{2}$ Rehabilitation Medicine, Department of Health Sciences, Linköping University, Linköping, Sweden \\ Email: ${ }^{*}$ bjorn.borsbo@liu.se
}

Received 7 April 2015; accepted 22 May 2015; published 25 May 2015

Copyright (C) 2015 by authors and Scientific Research Publishing Inc.

This work is licensed under the Creative Commons Attribution International License (CC BY). http://creativecommons.org/licenses/by/4.0/

\section{Abstract}

Background: Patients with acquired brain injury often experience impaired working memory (WM), a condition that can make everyday life activities and work difficult. Objectives: This study investigates the effects of computerized WM training on WM skills, cognitive tests, activity performance and estimated health and whether the effects of computerized WM training can be attributed to sex or time since injury. Methods: Forty-eight patients with acquired brain injury underwent computerized WM training. Patients were tested by a neuropsychologist and interviewed by an occupational therapist just prior and 20 weeks after completion of training. Results: Patients who participated in computerized WM training significantly improved their WM skills shown in WM index, their neuropsychological test scores, and their self-estimated health scores. They also significantly improved their performance of individually defined WM-related everyday activities and their satisfaction with the performance of these activities. There was a significant difference in terms of WM index, WM-related daily activity performance, and satisfaction with respect to time since injury. Conclusion: Computerized WM training can improve cognitive and everyday performance for patients with acquired brain injury. Patients can improve their cognitive functions a long time after suffering a brain injury or disease. This effect is greater if WM training is used early in the rehabilitation.

\section{Keywords}

Working Memory, Brain Injury, Rehabilitation, Adults

\section{Introduction}

The consequences of a brain injury can vary greatly, from almost full recovery to severe motor and cognitive impairments. How patients experience their residual state is affected by the consequences of brain damage in

\footnotetext{
${ }^{*}$ Corresponding author.
}

How to cite this paper: Hellgren, L., Samuelsson, K., Lundqvist, A. and Börsbo, B. (2015) Computerized Training of Working Memory for Patients with Acquired Brain Injury. Open Journal of Therapy and Rehabilitation, 3, 46-55. 
terms of impaired physical and cognitive function [1]. Typically, patients with acquired brain injury are initially focused on their physical impairments as cognitive impairments experienced after brain injury are often more subtle and harder to understand than physical impairments [2]. Furthermore, cognitive impairments can cause frustration for the patient and unreasonable expectations from others [3]. This frustration and unreasonable expectations are often the result of impaired working memory (WM), a typical consequence of acquired brain injury [4].

WM is the ability to maintain limited information in memory for a short time while using the information [5]. WM is required for many cognitive abilities and is closely linked to attention, especially the ability to control attention and to resist distractions [6]-[9]. WM is also important for well-functioning reasoning, planning and implementing a behaviour and proper verbal flow [10]-[12].

Patients with impaired WM often have problems concentrating (thus they need to do one thing at a time), learning, and following conversations (especially if the interaction includes several people) [13]. Clearly, WM is important for targeted meaningful cognitive functioning [14]. Moreover, reduced WM affects the possibility to recover from a stroke and return to work, conditions that are very important for a patient's quality of life [4] [6] [15].

Several studies investigating the influence of WM training on brain structures [11] [16]-[18] have shown that WM training can lead to changes in the frontal and parietal areas of the brain, such as increasing the number of dopamine receptors available in the prefrontal and parietal areas of the brain, areas that are responsible for WM [11] [16] [17] [19].

Cognitive function and the ability to improve WM are influenced by complex and changeable factors as well as training, although genetics also affects brain plasticity [20]. Takeuchi et al. found that WM training produces structural changes in white matter in the frontal cortex and inferior parts of the parietal cortex, changes that increase the ability to efficiently send signals between nerve cells in these areas [21]. The plasticity of the brain allows for the possibility to train even an injured brain [22]; several studies have shown that WM training can improve WM after acquired brain injury [23]-[30]. For example, Lundqvist et al. showed that WM training leads to improvements in neuropsychological tests as well as in the ability to cope with everyday life in 21 patients with acquired brain injury [23]. Several studies clearly show that WM associated with acquired brain injury can be improved using several types of interventions [23]-[30]; however, because these studies have a relatively limited number of participants (ranging from one participant to 24), more studies are needed to evaluate the effectiveness of the various training methods. The present study is indented to add knowledge in this field including the aspects of gender and time since injury.

\section{Aims}

This study investigates the effects of computerized WM training on WM skills, cognitive tests, activity performance and estimated health. In addition, this study investigates whether the effects of computerized WM training can be attributed to gender or time since injury.

\section{Methods}

\subsection{Subjects}

The subjects for this study were patients with non-progressive acquired brain injury who participated in a computerized WM training program (Cogmed QM) [31] at a Rehabilitation Medicine department in Sweden between 2009 and 2012. Forty-eight patients met the clinical criteria for inclusion in WM training and chosed to participate. The participants did not have any co-morbidity that could have any significant effect on working memory.

The inclusion criteria were age 20 - 65 years, subjective WM impairment, significantly impaired WAIS WM index compared with index of verbal comprehension measured and/or index of perceptual organization or a WAIS WM index $<80$ as measured by the WAIS-III, and motivated for training. The exclusion criteria were IQ $\leq 70$ as measured with WAIS-III/WAIS-IV, depression according to DSM-IV, and perceptual or motor difficulties that make the computerized WM training impossible.

\subsection{Methods}

\subsubsection{Neuropsychological Testing}

A neuropsychologist performed all neuropsychological tests, which were conducted before and 20 weeks after 
WM training. The neuropsychological tests were administered in the same order each time. The included tests were well-known neuropsychological tests focusing on verbal and visual working memory:

- Paced Auditory Serial Attention Test (PASAT 2.4). This test measures WM, information processing speed and the ability to sustain and divide attention. The task requires the patient to recite a long series of digits read aloud after a short interval; then, patient adds the digit they just heard with the preceding digits [32] [33].

- Forward and backward block repetition. The test contains ten blocks that are irregularly placed on a plate. The test leader points to the blocks in a certain order and the patient's task is to point to the blocks in the same order (forward block repeat) and reverse (backward block repeat). The number of blocks that the test leader points to varies between two and eight blocks [33] [34].

- Listening Span Task. The test consists of sentences with three words presented in groups of three to six sentences. The task is to answer "yes" or "no" depending on whether the sentence is meaningful or nonsense. Then, the participants are asked to reproduce either the first or the last word, not knowing which in advance [35] [36].

\subsubsection{Working Memory-Related Activities, Quality of Life, and Health}

An occupational therapist asked all patients to complete the EQ-5D questionnaire and performed all the interviews based on the Canadian Occupational Performance Measure (COPM), on WM-related activity performance and satisfaction. The questionnaire and the interviews were performed before and 20 weeks after WM training.

- Canadian Occupational Performance Measure (COPM) was used to gather information about the patients' perception of performance and satisfaction with performance in those activities that were of importance to the patient but difficult to perform due to WM impairment as the result of brain injury. During the interviews, the therapist also asked the patients about their satisfaction with their occupational performance. When the most important activities were identified, the patient scored his/her performance and satisfaction with that performance for each identified activity. The scoring was done on two scales from 1 - 10 ( 1 = cannot do it/not satisfied at all and $10=$ can make it extremely well/extremely satisfied). An improvement between the two scorings (baseline and follow-up) of at least two scale units is considered a clinically important difference-CID [37].

- EQ-5D is a self-assessment questionnaire of a person's perceived state of health. The questionnaire is not cognitively demanding and takes little time to complete. It consists of two parts. In the first part, the patient estimates the degree of severity of his/her problems in five areas: mobility, self-care, usual activities, pain/discomfort and anxiety/depression. The combinations of responses are then aggregated into a measure of healthrelated quality of life index (EQ-5D Index). In the second part, the patients estimate their perceived health on a VAS scale (EQ-VAS) ranging from 0 to $100(0=$ worst imaginable health state, $100=$ best imaginable health state [38]-[41]. The patients completed the questionnaire before and 20 weeks after completion of WM training.

\subsubsection{WM Training}

The computerized WM training program Cogmed (QM) was used [31]. The training program consists of various visuo-spatial and verbal working memory tasks. The difficulty of each task is automatically adapted to each patient's WM capacity. After completing the 25 training sessions, each individual was assigned a WM index (the difference between the two best results (max index) and results from day two and three (start index), which represents the change in WM.

The subjects performed their WM training program on a computer (PC), and each session was 45 - 60 minutes of intense exercise including one break. The exercise intensity varied between four and five days/week for five to seven weeks. All subjects trained in pairs or in groups of three in a quiet, private room at the Department of Rehabilitation Medicine. One of three certified coaches (OTs) was present in the room during every training session. Once a week, the coaches provided specific feedback. The patients also received continuous feedback from the computer program. Both individual performances and group performances were analyzed and presented at a 20-week follow-up session. Each individual was then encouraged to provide feedback about their experiences and asked whether they had noticed any long-term effects from the training. No other therapies were applied during the examination period.

\subsection{Statistics}

Data were analyzed using the IBM SPSS Statistics 21. Outcome was presented as mean \pm 1 standard deviation or median and range. The accepted level of significance was $\mathrm{p} \leq 0.05$. Difference between groups and results 
before versus after training were analyzed using the Mann-Whitney U-test, the Chi-square test (sex), and Wilcoxon sign rank test. For correlation analyses, Spearman's rank correlation test was used.

\subsection{Ethical Considerations}

Before the present intervention was introduced as a standard training program in the clinic, a randomized controlled study (approved by the local research ethics committee, Dnr 187-06) with a cross-over design was conducted [23]. The present study was based on the same standard procedures as in the controlled study which was implemented into clinical practice using the same criteria and outcome instruments. All information has been collected from medical records and test forms summarized by the rehabilitation team. Included subjects were not subjected to any special measures beyond those included in clinical routines. The authors of this study only had access to anonymized data.

\section{Results}

\subsection{Background Data}

This study included 48 consecutive subjects (30 men and 18 women) with a mean age of 43.7 years (median 44 years) and mean time since injury of 51.2 month (median 29 month). All the patients who started the training also completed the WM training, but some data from the after training (20 weeks post training) were missing for three patients because they for different reasons did not perform the final testing. The cause of brain injury included intra cerebral infarction (23\%), traumatic brain injury (21\%), infection (19\%), intra cerebral hemorrhage (13\%), subarachnoid hemorrhage (10\%), brain tumor (8\%) and other (6\%).

\subsection{Results for the Whole Group}

The results for the various neuropsychological tests before and 20 weeks after completion of training revealed that the group had made significant improvements on all tests $(\mathrm{p}<0.001)$ (Table 1$)$. The difference in WM index was significantly positive $(\mathrm{p}<0.001)$. The start index and max index confirmed that all patients had improved their WM index during the training period.

The improvement in perceived activity performance and satisfaction with performance as measured with the COPM before and 20 weeks after training were significant $(\mathrm{p}<0.001)$ (Table 1$)$. The patients indicated that they managed important WM-related activities better 20 weeks after training; they were also more satisfied with their performance of the identified activities. Mean estimations before and after training were compared at an individual level: $49 \%$ of the patients had an improvement of at least two scale-stages on activity performance and $51 \%$ had the same improvement on satisfaction with performance [37].

There was a positive correlation between the difference in WM index and the difference in patients' estimated activity performance from before versus 20 weeks after the WM training ( $r s=0.536, \mathrm{p}<0.001$ ) (Figure 1 ). The

Table 1. Mean values (SD) before start of working memory training compared to results 20 weeks after training.

\begin{tabular}{|c|c|c|c|}
\hline & Before M (SD) & 20 weeks after M (SD) & p-value \\
\hline PASAT & $38.9(11.1)$ & $44.0(11.0)$ & $<0.001$ \\
\hline Listening span & $24.3(6.1)$ & $27.3(5.3)$ & $<0.001$ \\
\hline Forward block repetition & $7.5(1.9)$ & $8.9(1.7)$ & $<0.001$ \\
\hline Backward block repetition & $7.0(1.7)$ & $8.4(1.7)$ & $<0.001$ \\
\hline COPM performance & $3.8(1.2)$ & $5.5(1.7)$ & $<0.001$ \\
\hline COPM satisfaction & $3.2(1.8)$ & $5.4(1.8)$ & $<0.001$ \\
\hline EQ-5D index & $0.62(0.30)$ & $0.69(0.25)$ & 0.009 \\
\hline EQ-VAS & $56.6(21.0)$ & $63.8(17.7)$ & $<0.001$ \\
\hline
\end{tabular}

Paced Auditory Serial Attention Test (PASAT), Canadian Occupational Performance Measure (COPM), European Quality of Life Instrument-Five dimensions (EQ-5D), European Quality of Life Instrument-100 Points Health Scale (EQ-VAS). 


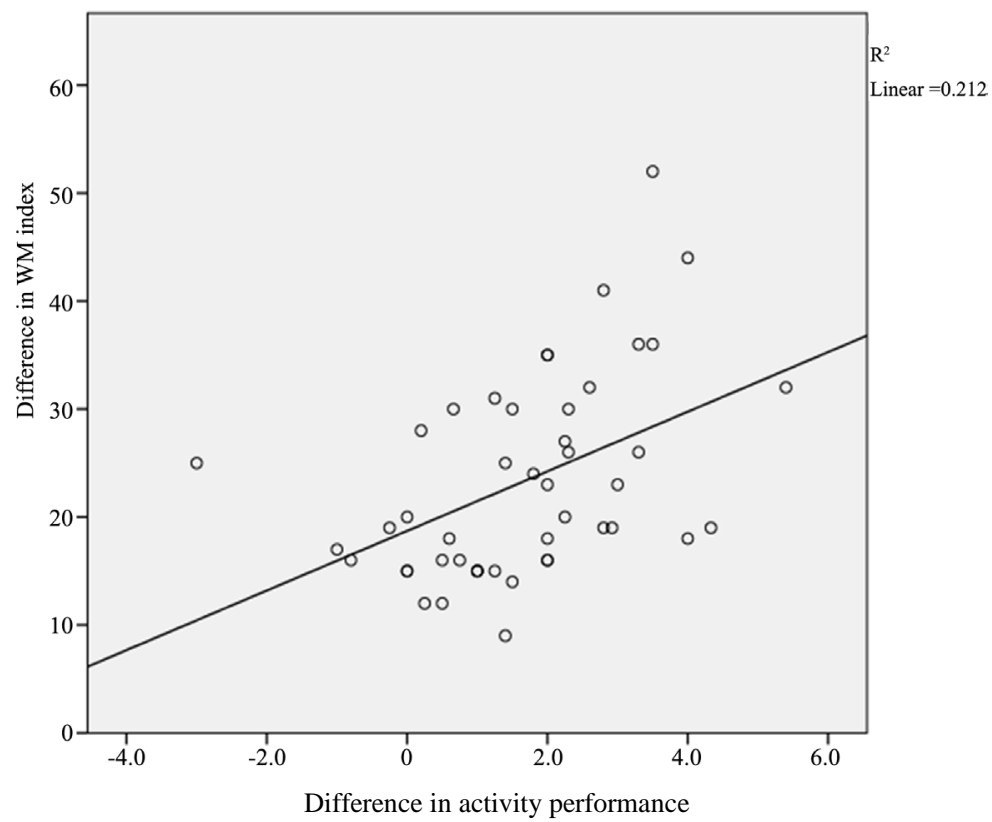

Figure 1. Correlation between the difference in WM index and the difference in activity performance (COPM), before versus 20 weeks after WM training. $\left(\mathrm{r}_{\mathrm{s}}=0.536, \mathrm{p}<0.001\right)$.

correlation between the difference in WM index and the difference in the patients' estimated satisfaction with activity performance before versus 20 weeks after WM training, however, was not significant $\left(r_{s}=0.226, p=\right.$ 0.127) (Figure 2).

Health-related quality of life as measured by EQ-5D Index showed a significant positive change $(p=0.009)$ from before training versus 20 weeks after training. In addition, a positive change in perceived health (as measured by EQ-VAS) from before versus 20 weeks after training was found $(\mathrm{p}<0.001)$ (Table 1$)$.

\subsection{Sex Differences}

No significant sex differences were found in terms of age, time since injury, or education. No differences between men and women were found in results related to neuropsychological test performance as measured before versus 20 weeks after completion of training (Table 2). There was no difference between men and women related to the change in WM index (starting index compared with max index) $(\mathrm{p}=0.586)$. There was no difference between men and women related to the change in perceived activity performance or satisfaction with performance as measured using the COPM, before versus 20 weeks after completion of training (Table 2). For estimated occupational performance as well as satisfaction with performance, $47 \%$ of the women had an improvement of at least two scale units. The corresponding results for men were $50 \%$ and $53 \%$, respectively. There was no difference between men and women in change of HRQoL as measured by EQ-5D Index before versus 20 weeks after training (Table 2). Similarly, there was no difference between men and women in the change of perceived health as measured by the EQ-VAS before versus 20 weeks after training (Table 2).

\subsection{Differences Related to Time since Injury}

The subjects were divided into two groups according to the time elapsed since injury. One group $(\mathrm{n}=13)$ consisted of individuals whose time since injury had been > 18 months; for the second group $(n=34), \leq 18$ months had passed since injury onset. No significant differences were found between these groups concerning age, gender, or education.

When comparing the two groups concerning difference in neuropsychological test results, as measured before versus 20 weeks after training, there were no significant differences between these groups (Table 3). The difference in WM index was significant positive in both groups respectively ( $\leq 0.001$ for both groups). However, the difference of the change in WM index (starting index compared with max index) between the two groups 


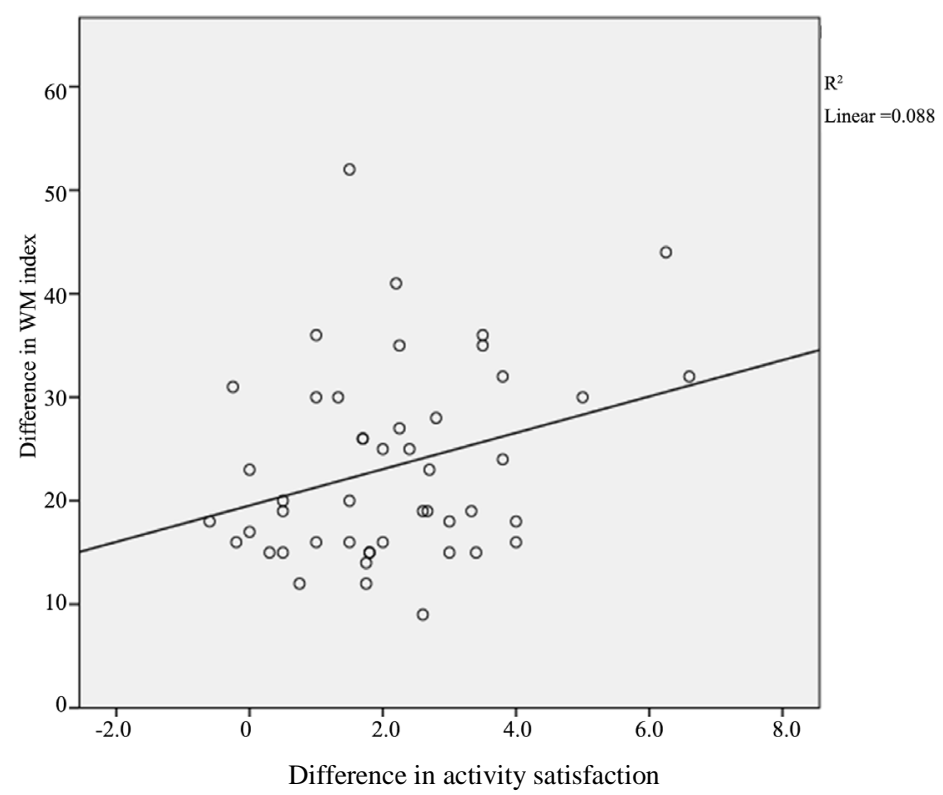

Figure 2. Correlation between the difference in WM index and the difference in activity satisfaction (COPM), before versus 20 weeks after WM training. $\left(r_{\mathrm{s}}=0.226, \mathrm{p}=0.127\right)$.

Table 2. Mean values (SD) change of results before start of working memory training compared to results 20 weeks after training. Women and men compared.

\begin{tabular}{cccc}
\hline & $\begin{array}{c}\text { Women-change } \\
\text { (before and after training). M (SD) (before and after training). M (SD) }\end{array}$ & p-value \\
\hline PASAT & $4.6(6.1)$ & $4.3(7.5)$ & 0.903 \\
Listening span & $2.5(3.0)$ & $2.7(4.4)$ & 0.886 \\
Forward block repetition & $1.1(1.8)$ & $1.6(1.6)$ & 0.352 \\
Backward block repetition & $2.2(2.3)$ & $0.9(1.8)$ & 0.059 \\
COPM performance & $1.8(2.0)$ & $1.6(1.3)$ & 0.765 \\
COPM satisfaction & $2.1(1.6)$ & $2.2(1.6)$ & 0.782 \\
EQ-5D index & $0.10(0.21)$ & $0.08(0.22)$ & 0.805 \\
EQ-VAS & $10.1(14.5)$ & $7.1(13.9)$ & 0.635 \\
\hline
\end{tabular}

Paced Auditory Serial Attention Test (PASAT), Canadian Occupational Performance Measure (COPM), European Quality of Life Instrument-Five dimensions (EQ-5D), European Quality of Life Instrument-100 Points Health Scale (EQ-VAS).

Table 3. Mean values (SD) change of results before start of working memory training compared to results 20 weeks after training. One group with 18 months or less since the time of injury $(n=13)$, the second group with more than 18 months since the time of injury $(n=34)$.

\begin{tabular}{cccc}
\hline & $\begin{array}{c}\text { 18 months-change before and } \\
\text { after training M(SD) }\end{array}$ & $\begin{array}{c}>18 \begin{array}{c}\text { months-change before and } \\
\text { after training M (SD) }\end{array} \\
\text { p-value }\end{array}$ \\
PASAT & $2.8(5.1)$ & $5.2(7.5)$ & 0.193 \\
Listening span & $2.0(3.6)$ & $2.9(4.1)$ & 0.347 \\
Forward block repetition & $1.0(1.8)$ & $1.5(1.7)$ & 0.537 \\
Backward block repetition & $0.7(2.4)$ & $1.56(1.9)$ & 0.108 \\
COPM performance & $2.5(1.3)$ & $1.4(1.5)$ & $<0.05$ \\
COPM satisfaction & $3.1(1.9)$ & $1.8(1.3)$ & $<0.05$ \\
EQ-5D index & $0.09(0.11)$ & $0.10(0.23)$ & 0.298 \\
EQ-VAS & $5.7(10.9)$ & $9.1(15.3)$ & 0.572 \\
\hline
\end{tabular}

Paced Auditory Serial Attention Test (PASAT), Canadian Occupational Performance Measure (COPM), European Quality of Life Instrument-Five dimensions (EQ-5D), European Quality of Life Instrument-100 Points Health Scale (EQ-VAS). 
was significant $(\mathrm{p}<0.05)$. The group with $\leq 18$ months since injury exhibited more improvement in WM index than the group with $>18$ months since injury.

The improvement in perceived activity performance and satisfaction with performance as measured with the COPM before and 20 weeks after training were significant for both groups respectively $(\mathrm{p} \leq 0.002)$. The difference of change in subject's estimation of occupational performance and satisfaction with performance, before versus 20 weeks after completion of training, was significant for both groups $(\mathrm{p}<0.05)$ (Table 3). The group with $\leq 18$ months had a greater positive change in both self-estimated occupational performance and satisfaction with performance, than the group $>18$ month. In the group $\leq 18$ months after injury, $77 \%$ exhibited an improvement of at least two scale units (the level considered as a clinical important difference) in terms of occupational performance and 69\% exhibited the same level of improvement in satisfaction with performance. In the group > 18 months, the corresponding results of improvement were 39\% for occupational performance and 45\% for satisfaction with performance. There was no difference in change of health-related quality of life and estimated health (measured by EQ-5D Index and EQ-VAS before and 20 weeks after WM training) between the two groups (Table 3)

\section{Discussion}

Main findings: All patients' WM index improved after WM training. Cognitive functions, as measured by WM related neuropsychological tests, improved as well as performance of important WM-related everyday activities and satisfaction with these performances. The subjects estimated a higher quality of life after WM training compared to before training, and perceived health was improved (Table 1). There were no gender differences in outcome, but there were significant differences depending on time since injury (Table 3). The individuals with < 18 months since injury improved more, with respect to WM index, everyday occupational performance, and satisfaction with that performance, than those with $\geq 18$ months since injury (Table 3 ).

Apparently, computerized WM training had a good effect in subjects with acquired brain injury both on the tasks directly trained in the program (WM index), other WM-related tasks that emerged in neuropsychological tests and above all on the patients' everyday working memory related and prioritized activities. Although some of these positive effects have been reported in other studies [23] [25] [29] [30], the results in this study additionally shows that the effects from the WM-training makes an impact in the individuals everyday life as shown by improved occupational performance and satisfaction with that performance. Results from a previous study also showed an improvement in perceived health as measured by VAS after working memory training [23], a finding also confirmed by this study. This study also found an improvement in health related quality of life, as measured by EQ-5D Index.

Other studies have shown that women with traumatic brain injury managed to do WM-intensive tasks better than men with the same injury [42]. Furthermore, studies have provided detailed descriptions on how male versus female brains deal differently with cognitive processes [43]. In this study, we found no differences in effects with respect to sex (Table 2). However, we had a mixed group with respect of cause of injury. As a result, sex or cause of injury, might not be a factor to take into account when deciding whether a patient should be offered WM training.

In contrast to a study by Johansson et al. [25], the present study revealed differences in WM index depending on how much time had passed since injury. These differences may be because the mean time post injury differed by several years: in our study the patients who improved the most belonged to the group $<18$ months since injury and in Johansson et al.'s study the majority of the patients' time since injury was $>18$ months. Since $39 \%$ of the individuals who belonged to the group $>18$ months since injury estimated a clinically significant improvement in perceived occupational performance, compared to $77 \%$ of the individuals who belonged to the group < 18 months since injury - this means that even though WM training has an impact on everyday life a long time after the injury, this impact seems to be greater if the WM training is completed earlier after injury. Early rehabilitation is known to be important for the functional outcome in stroke patients [44], and the same relationship seems evident in the outcome of WM training after acquired brain injury, irrespective of cause. However, WM training seems to be beneficial also long after a brain injury has occurred.

Methodological considerations: A limitation of this study is that there was no control group. However, previous research with the same design and method has shown that spontaneous recovery during the study period seems to be negligible and that the test-retest effect cannot explain the improvement between test sessions [23]. 
Further, the authors could not find a definition in the literature of what is considered "long time since injury" when defining the two groups to compare related to time since injury. The groups in this study were selected mainly from clinical experience of the rehabilitation process of this category of patients.

A strength of our study is its large sample size: previous studies relied on fewer participants [23]-[30]. Another strength is that we evaluated the effects of WM training using several methods-e.g., reflecting both trained (WM index) and untrained (neuropsychological tests) WM tasks. The evaluation also included an investigation of the outcome in patients' everyday life, in terms of individually identified occupations of importance (COPM). The fact that data collection was done before and 20 weeks after training, rather than directly after training, can also be seen as strength. That is, the 20-week evaluation might produce more realistic accounts of daily activities than merely relying on patient evaluations conducted immediately after WM training, since the intensity of the WM training period, and the fact that it offered structure and attention could have affected the results from the data collection if data had been collected immediately after the training period.

\section{Clinical Implications}

Computerized WM training is effective for patients with acquired brain injury. Despite the change in training intensity compared to other studies [23] [25] [29] [30], our study produces good results. The change in training intensity makes the demanding training less so and therefore more patients might be able to cope with the training. This study shows that some patients whose injuries occur more than 18 months before WM training improve more; however, this improvement may have been even greater if the training has occurred even earlier. As it may be valuable for patients to receive this training soon after their injury, rehabilitation teams should make an early assessment of need. At the same time, it is important to keep in mind that training can have an effect even a long time after injury, so WM training can be beneficial for a lot of patients with working memory dysfunction after a brain injury despite time since injury. However, the expectations associated with later stage training should be somewhat lower.

\section{Further Studies}

The influence time should be further investigated after injury has on the effects from WM training. Is there a cut-off limit of time after injury when a possible improvement after WM training is no longer clinically relevant? It would also be interesting to further investigate whether or not age influences the possibilities of improvement from computerized WM training, as several cognitive functions, including working memory, develop and settle at different ages in normal development [45].

\section{References}

[1] Roding, J., Glader, E.-L., Malm, J., Eriksson, M. and Lindström, B. (2009) Perceived Impaired Physical and Cognitive Functions after Stroke in Men and Women between 18 and 55 Years of Age-A National Survey. Disability and Rehabilitation, 31, 1092-1099. http://dx.doi.org/10.1080/09638280802510965

[2] Bendz, M. (2000) Rules of Relevance after a Stroke. Social Science \& Medicine, 51, 713-723. http://dx.doi.org/10.1016/S0277-9536(99)00486-4

[3] Stone, S.D. (2005) Reactions to Invisible Disability: The Experiences of Young Women Survivors of Haemorrhagic Stroke. Disability and Rehabilitation, 27, 293-304. http://dx.doi.org/10.1080/09638280400008990

[4] van Zomeren, A.H. and W. van den Burg (1985) Residual Complaints of Patients Two Years after Severe Head Injury. Journal of Neurology, Neurosurgery \& Psychiatry, 48, 21-28. http://dx.doi.org/10.1136/jnnp.48.1.21

[5] Nyberg, L. (2002) Kognitiv Neurovetenskap. Studentlitteratur, Lund.

[6] Robertson, I.H. and Murre, J.M.J. (1999) Rehabilitation of Brain Damage; Brain Plasticity and Principles of Guided Recovery. Psychological Bulletin, 125, 544-575. http://dx.doi.org/10.1037/0033-2909.125.5.544

[7] Taylor, S.F., Welsh, R.C., Wager, T.D., Phan, K.L., Fitzgerald, K.D. and Gehring, W.J. (2004) A Functional Neuroimaging Study of Motivation and Executive Function. Neuroimage, 21, 1045-1054. http://dx.doi.org/10.1016/j.neuroimage.2003.10.032

[8] Shipstead, Z., Redick, T.S., Hicks, K.L. and Engle, R.W. (2012) The Scope and Control of Attention as Separate Aspects of Working Memory. Memory, 20, 608-628. http://dx.doi.org/10.1080/09658211.2012.691519

[9] de Fockert, J.W., Rees, G., Frith, C.D. and Lavie, N. (2001) The Role of Working Memory in Visual Selective Atten- 
tion. Science, 291, 1803-1806. http://dx.doi.org/10.1126/science.1056496

[10] Klingberg, T., Fernell, E., Olesen, P.J., Johnson, M., Gustafsson, P., Dahlström, K., Gillberg, C.G., Forssberg, H. and Westerberg, H. (2005) Computerized Training of Working Memory in Children with ADHD-A Randomized, Controlled Trial. Journal of the American Academy of Child \& Adolescent Psychiatry, 44, 177-186. http://dx.doi.org/10.1097/00004583-200502000-00010

[11] D’Esposito, M., Postle, B.R. and Rypma, B. (2000) Prefrontal Cortical Contributions to Working Memory: Evidence from Event-Related fMRI Studies. Experimental Brain Research, 133, 3-11. http://dx.doi.org/10.1007/s002210000395

[12] Bittner, R.M. and Crowe, S.F. (2007) The Relationship between Working Memory, Processing Speed, Verbal Comprehension and FAS Performance Following Traumatic Brain Injury. Brain Injury, 21, 709-719. http://dx.doi.org/10.1080/02699050701468917

[13] Vallat-Azouvi, C., Pradat-Diehl, P. and Azouvi, P. (2012) The Working Memory Questionnaire: A Scale to Assess Everyday Life Problems Related to Deficits of Working Memory in Brain Injured Patients. Neuropsychological Rehabilitation: An International Journal, 22, 634-649. http://dx.doi.org/10.1080/09602011.2012.681110

[14] Kennedy, M.R., Coelho, C., Turkstra, L., Ylvisaker, M., Sohlberg, M.M., et al. (2008) Intervention for Executive Functions after Traumatic Brain Injury: A Systematic Review, Meta-Analysis and Clinical Recommendations. Neuropsychological Rehabilitation: An International Journal, 18, 257-299. http://dx.doi.org/10.1080/09602010701748644

[15] Vestling, M., Tufvesson, B. and Iwarsson, S. (2003) Indicators for Return to Work after Stroke and the Importance of Work for Subjective Well-Being and Life Satisfaction. Journal of Rehabilitation Medicine, 35, 127-131. http://dx.doi.org/10.1080/16501970310010475

[16] Olesen, P.J., Westerberg, H. and Klingberg, T. (2004) Increased Prefrontal and Parietal Activity after Training of Working Memory. Nature Neuroscience, 7, 75-79. http://dx.doi.org/10.1038/nn1165

[17] McNab, F., Varrone, A., Farde, L., Jucaite, A., Bystritsky, P., et al. (2009) Changes in Cortical Dopamine D1 Receptor Binding Associated with Cognitive Training. Science, 323, 800-802. http://dx.doi.org/10.1126/science.1166102

[18] Nordvik, J.E., Schanke, A.-K., Walhovd, K., Fjell, A., Grydeland, H., et al. (2012) Exploring the Relationship between White Matter Microstructure and Working Memory Functioning Following Stroke: A Single Case Study of Computerized Cognitive Training. Neurocase: The Neural Basis of Cognition, 18, 139-151. http://dx.doi.org/10.1080/13554794.2011.568501

[19] Westerberg, H. and Klingberg, T. (2007) Changes in Cortical Activity after Training of Working Memory-A SingleSubject Analysis. Physiology \& Behavior, 92, 186-192. http://dx.doi.org/10.1016/j.physbeh.2007.05.041

[20] Brehmer, Y., Westerberg, H., Bellander, M., Fürth, D., Karlsson, S., et al. (2009) Working Memory Plasticity Modulated by Dopamine Transporter Genotype. Neuroscience Letters, 467, 117-1120.

http://dx.doi.org/10.1016/j.neulet.2009.10.018

[21] Takeuchi, H., Sekiguchi, A., Taki, Y., Yokoyama, S., Yomogida, Y., et al. (2010) Training of Working Memory Impacts Structural Connectivity. Journal of Neuroscience, 30, 3297-3303. http://dx.doi.org/10.1523/JNEUROSCI.4611-09.2010

[22] Grimby, G., Eriksson, P., Nilsson, M. and Sjölund, B. (2003) [Neurobiology Provides a Scientific Foundation for Rehabilitation. Report from an International Symposium]. Lakartidningen, 100, 2052-2055.

[23] Lundqvist, A., Grundström, K., Samuelsson, K. and Rönnberg, J. (2010) Computerized Training of Working Memory in a Group of Patients Suffering from Acquired Brain Injury. Brain Injury, 24, 1173-1183. http://dx.doi.org/10.3109/02699052.2010.498007

[24] Westerberg, H., Hirvikoski, T., Forssberg, H. and Klingberg, T. (2004) Visuo-Spatial Working Memory Span: A Sensitive Measure of Cognitive Deficits in Children with ADHD. Child Neuropsychology, 10, 155-161. http://dx.doi.org/10.1080/09297040409609806

[25] Johansson, B. and Tornmalm, M. (2012) Working Memory Training for Patients with Acquired Brain Injury: Effects in Daily Life. Scandinavian Journal of Occupational Therapy, 19, 176-183. http://dx.doi.org/10.3109/11038128.2011.603352

[26] Serino, A., Ciaramelli, E., Di Santantonio, A., Malagù, S., Servadei, F., et al. (2007) A Pilot Study for Rehabilitation of Central Executive Deficits after Traumatic Brain Injury. Brain Injury, 21, 11-19. http://dx.doi.org/10.1080/02699050601151811

[27] McDowell, S., Whyte, J. and D’Esposito, M. (1998) Differential Effect of a Dopaminergic Agonist on Prefrontal Function in Traumatic Brain Injury Patients. Brain, 121, 1155-1164. http://dx.doi.org/10.1093/brain/121.6.1155

[28] Vallat, C., Azouvi, P., Hardisson, H., Meffert, R., Tessier, C., et al. (2005) Rehabilitation of Verbal Working Memory after Left Hemisphere Stroke. Brain Injury, 19, 1157-1164.

[29] Akerlund, E., Esbjörnsson, E., Sunnerhagen, K.S. and Björkdahl, A. (2013) Can Computerized Working Memory 
Training Improve Impaired Working Memory, Cognition and Psychological Health? Brain Injury, 27, 1649-1657. http://dx.doi.org/10.3109/02699052.2013.830195

[30] Bjorkdahl, A., Åkerlund, E., Svensson, S. and Esbjörnsson, E. (2013) A Randomized Study of Computerized Working Memory Training and Effects on Functioning in Everyday Life for Patients with Brain Injury. Brain Injury, 27, 16581665. http://dx.doi.org/10.3109/02699052.2013.830196

[31] Westerberg, H. (2008) Working Memory; Development, Disorders and Training, in Department of Women and Child Health. Karolinska Institutet, Stockholm.

[32] Grönwall, D. (1977) Paced Auditory Serial-Addition Task: A Measure of Recovery from Concussion. Perceptual and Motor Skills, 44, 367-373. http://dx.doi.org/10.2466/pms.1977.44.2.367

[33] Strauss, E., Sherman, E. and Spreen, O. (2006) A Compendium of Neuropsychological Tests. 3rd Edition, Oxford University Press, New York.

[34] Nyman, H. and Johansson, C. (2004) WAIS-III-NI: WAIS III Som Neuropsykologiskt Instrument. Hartcourt Assessment, Stockholm.

[35] Daneman, M. and Carpenter, P.A. (1980) Individual Differences in Working Memory and Reading. Journal of Verbal Learning and Verbal Behaviour, 19, 450-466. http://dx.doi.org/10.1016/S0022-5371(80)90312-6

[36] Conway, A.R.A., Kane, M.J., Bunting, M.F., Zach Hambrick, D., Wilhelm, O., et al. (2005) Working Memory Span Tasks: A Methodological Review and User’s Guide. Psychonomic Bulletin \& Review, 12, 769-786. http://dx.doi.org/10.3758/BF03196772

[37] Law, M., Paptiste, S., McColl, M.A., Polatajko, H. and Pollock, N. (1991) Canadian Occupational Performance Measure Manual. CAOT, Toronto.

[38] EuroQol Group (1990) EuroQol—A New Facility for the Measurement of Health-Related Quality of Life. Health Policy, 16, 199-208. http://dx.doi.org/10.1016/0168-8510(90)90421-9

[39] Brooks, R., EuroQol Group (1996) EuroQol: The Current State of Play. Health Policy, 37, 53-72. http://dx.doi.org/10.1016/0168-8510(96)00822-6

[40] Burström, K. (2002) Hälsorelaterad livskvalitet mätt med EQ-5D; Beskrivning av instrumentet samt resultat från en befolkningsundersökning i Stockholms län. Stockholms läns landsting, Socialmedicin, Samhällsmedicin, Karolinska Institutet, Stockholm.

[41] van Agt, H.M.E., Essink-Bot, M.-L., Krabbe, P.F.M. and Bonsel, G.J. (1994) Test-Retest Reliability of Health State Valuations Collected with the EuroQol Questionnaire. Social Science \& Medicine, 39, 1537-1544. http://dx.doi.org/10.1016/0277-9536(94)90005-1

[42] Ratcliff, J.J., Greenspan, A.I., Goldstein, F.C., Stringer, A.Y., Bushnik, T., et al. (2007) Gender and Traumatic Brain Injury: Do the Sexes Fare Differently? Brain Injury, 21, 1023-1030. http://dx.doi.org/10.1080/02699050701633072

[43] Draca, S. (2010) Gender-Specific Functional Cerebral Asymmetries and Unilateral Cerebral Lesion Sequelae. Reviews in the Neurosciences, 21, 421-425. http://dx.doi.org/10.1515/REVNEURO.2010.21.6.421

[44] Hu, M.-H., Hsu, S.-S., Yip, P.-K., Jeng, J.-S. and Wang, Y.-H. (2010) Early and Intensive Rehabilitation Predicts Good Functional Outcomes in Patients Admitted to the Stroke Intensive Care Unit. Disability and Rehabilitation, 32, 12511259. http://dx.doi.org/10.3109/09638280903464448

[45] Anderson, V., Jacobs, R. and Anderson, P.J. (2011) Executive Functions and the Frontal Lobes: A Lifespan Perspective. Taylor \& Francis, London. 